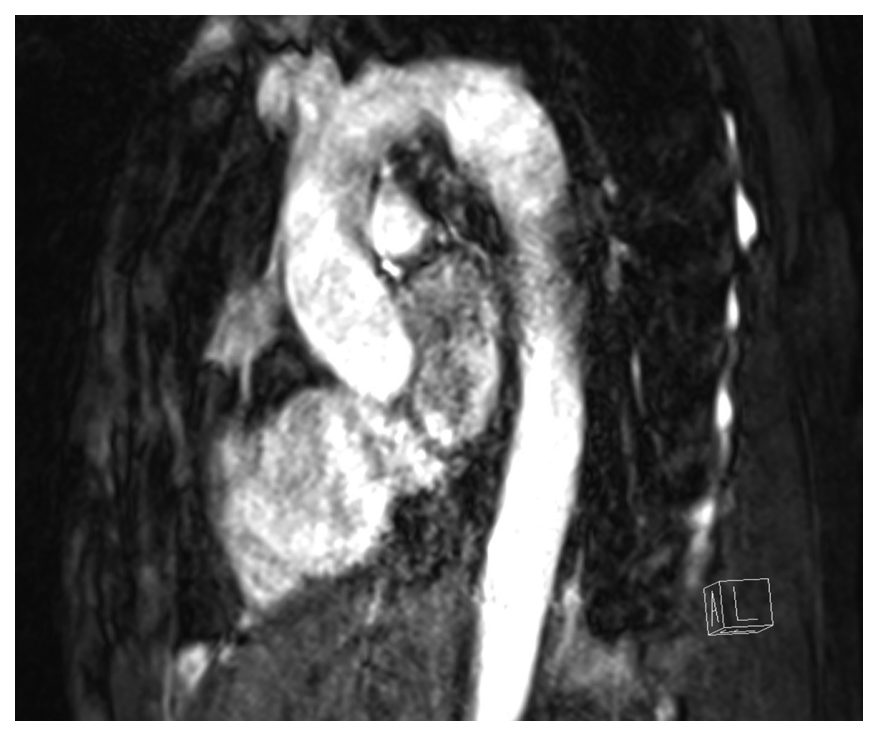

Abstract 19 Figure 1 Mildly dilated proximal descending aorta: 3D non-contrast MRA

Abstract 19 Table 1 Baseline characteristics and outcomes of pregnancy

\begin{tabular}{ll}
\hline Variable & $\mathrm{N}=15$ \\
\hline Age (years) & $27 \pm 4$ \\
Ethnicity & \\
White & $14(93)$ \\
Asian & $0(0)$ \\
Afro-Caribbean & $1(7)$ \\
Inherited Aortopathy & \\
Marfan & $9(60)$ \\
Ehlers-Danlos & $2(13)$ \\
Loeys-Dietz & $1(7)$ \\
Undefined & $3(20)$ \\
Beta-blocker & $12(80)$ \\
Systolic blood pressure (mmHg) & $121 \pm 9$ \\
Diastolic blood pressure (mmHg) & $76 \pm 4$ \\
Aortic dimensions & \\
Annulus (mm) & $25 \pm 8$ \\
Sinus of Valsava (mm) & $35 \pm 4$ \\
Sino-tubular junction (mm) & $29 \pm 6$ \\
Proximal ascending (mm) & $22 \pm 8$ \\
Mid aortic root (mm) & $26 \pm 5$ \\
Proximal descending (mm) & $25 \pm 11$ \\
Distal descending (mm) & $20 \pm 4$ \\
Quality of study (0 = poor, 3 = excellent) & $2.8 \pm 0.4$ \\
Gestational age at delivery (wk) & $38.0 \pm 0.5$ \\
Mode of delivery* & \\
Spontaneous vaginal delivery & $5(33)$ \\
Assisted (ventouse or forceps) & $3(20)$ \\
Induction & $4(27)$ \\
Elective Caesarian section & $3(20)$ \\
Emergency Caesarian section & $3(20)$ \\
Aortic dissection & \\
Maternal death & $1(7)$ \\
Healthy baby at delivery & $0(0)$ \\
\hline Dta ar meancy & $15(100)$ \\
\hline
\end{tabular}

Data are mean \pm SD or $\mathrm{N}(\%)$

${ }^{*}$ Not mutually exclusive
Conclusion Native SSFP MRA provides a robust and safe method to accurately measure the thoracic aorta in pregnant subjects with aortopathy, helping to inform decisions regarding the timing and mode of delivery.

\section{DO ATRIOPULMONARY (AP) FONTAN DIMENSIONS USING CMR INFLUENCE THE DEVELOPMENT OF ATRIAL TACHYARRHYTHMIA?}

*L Pickup, E Quinton, S Thorne, S Bowater, P Clift, JP de Bono, L Hudsmith. Department of Adult Congenital Heart Disease, University Hospital NHS Trust, The Queen Elizabeth Hospital Birmingham, UK

\subsection{6/heartjnl-2016-309668.20}

Introduction Atrial tachyarrhythmia is regarded as a late consequence of the Fontan circulation, particularly in those with an AP Fontan and is associated with significant morbidity and mortality. Developing methods to recognise those at the highest risk will allow early intervention, improving patient outcomes.

Purpose To establish relationship between AP Fontan chamber (FC) dimensions, ventricular volumes and function and the development of atrial arrhythmia (AR).

Methods Modified AP Fontan patients with CMR (1.5T, Avanto, Siemens) were reviewed (Figure 1). Horizontal long axis (HLA, TrueFISP cine, flip angle 80 , TR/TE $50 / 1.26 \mathrm{~ms}$, retrospective ECG gating) and transaxial 3D MRA non-contrast (Modified Siemens Whole Heart coronary artery sequence, respiratory navigator, ECG-triggered, free breathing, slice thickness $2.00 \mathrm{~mm}$ ) of the FC and the left atrium were examined.

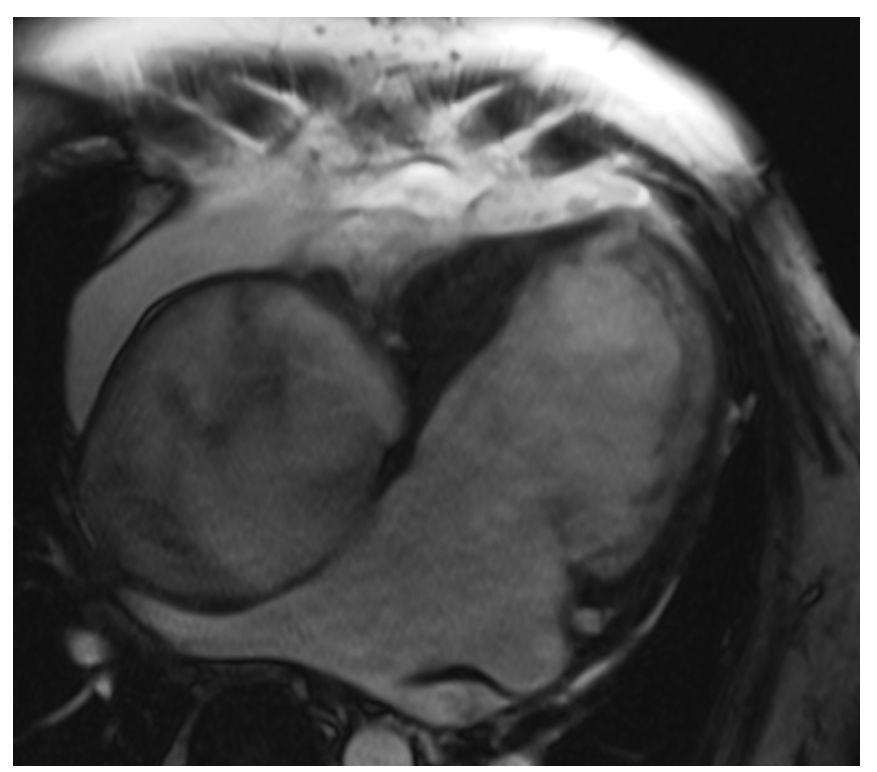

Abstract 20 Figure 1 HLA of 48 year old male with 5 ablations. Enddiastolic area of $69 \mathrm{~cm}^{2}$. Slow flow can be seen in the FC

Results 55 patients $58 \%$ female and $42 \%$ male, mean age $33 \mathrm{yrs}$ (SD 7.9). 32 patients suffered a documented AR, most commonly atrial flutter (79\%). There was a significant difference in age between the two groups with those having an AR tending to be older (36yrs vs 29 yrs $\mathrm{p}<0.05$ ) the age of procedure was also older in the AR group (11yrs vs. 6yrs p $<0.05)$ (Table 1). There was no difference in ventricular ejection 
Abstract 20 Table 1 Patient demographics and CMR parameters

\begin{tabular}{|c|c|c|c|}
\hline & $\begin{array}{l}\text { Non-arrhythmia } \\
\text { group } \\
\mathrm{N}=23 \\
\text { (Standard } \\
\text { deviation) }\end{array}$ & $\begin{array}{l}\text { Arrhythmia } \\
\text { Group } \\
\mathrm{N}=32 \\
\text { (Standard } \\
\text { Deviation) }\end{array}$ & \\
\hline Age (yrs) & 29(5) & $36(9)$ & $\begin{array}{l}P< \\
0.05^{*}\end{array}$ \\
\hline Age of Fontan Procedure (yrs) & $6(4)$ & $11(9)$ & $\begin{array}{l}P< \\
0.05^{*}\end{array}$ \\
\hline Ejection fraction (\%) & $55(11)$ & $55(12)$ & $\begin{array}{l}P> \\
0.05^{*}\end{array}$ \\
\hline $\begin{array}{l}\text { End Diastolic Area of Fontan chamber } \\
\left(\mathrm{cm}^{2}\right)\end{array}$ & 19(8) & $30(16)$ & $\begin{array}{l}P< \\
0.05^{*}\end{array}$ \\
\hline $\begin{array}{l}\text { End Diastolic Longitudinal Value of } \\
\text { Fontan Chamber }\left(\mathrm{cm}^{2}\right)\end{array}$ & $4(1)$ & $6(2)$ & $\begin{array}{l}P< \\
0.05^{*}\end{array}$ \\
\hline $\begin{array}{l}\text { End Systolic Area of Fontan Chamber } \\
\left(\mathrm{cm}^{2}\right)\end{array}$ & $23(11)$ & $32(16)$ & $\begin{array}{l}P< \\
0.05^{*}\end{array}$ \\
\hline $\begin{array}{l}\text { End Systolic longitudinal Value Fontan } \\
\text { Chamber }\left(\mathrm{cm}^{2}\right)\end{array}$ & $5(1)$ & $6(2)$ & $\begin{array}{l}P< \\
0.05^{*}\end{array}$ \\
\hline
\end{tabular}

*P values represent significance level of between group t-tests

fraction $(p>0.05)$. There were no significant differences in atrial parameters between the two groups $(p>0.05)$, however all measures of the FC were statistically different with larger measures occurring in the AR group $(\mathrm{p}<0.05)$. Receiver operator characteristic curves were constructed for each of the atrium and FC variables. End diastolic area and FC longitudinal dimension produced statistically significant results (ROC $0.745 \mathrm{P}<$ 0.05 and $0.719 \mathrm{p}<0.05)$. Using an upper limit of $27 \mathrm{~cm}^{2}$ for end diastolic FC area odds ratio of AR was 8.57 ( $\mathrm{p}<0.05$ ) with a sensitivity of 0.596 and a specificity of 0.870 .

Conclusions Increasing AP FC size is associated with increased risk of AR.

\section{FEATURE TRACKING CARDIAC MAGNETIC RESONANCE TO ASSESS LV MECHANICS IN DIFFERENT CARDIAC OVERLOAD CAUSED BY AORTIC VALVE DISEASE}

\section{${ }^{1, *}$ A Scatteia, ${ }^{2}$ E Mara Vollema, ${ }^{2}$ M Leung, ${ }^{2} \mathrm{~N}$ Ajmone Marsan, ${ }^{1} \mathrm{~A}$ Baritussio, ${ }^{1} \mathrm{E}$ De Garate, ${ }^{1}$ A Ghosh Dastidar, ${ }^{1} \mathrm{~J}$ Rodrigues, ${ }^{2} \mathrm{JJ}$ Bax, ${ }^{2} \mathrm{~V}$ Delgado, ${ }^{1} \mathrm{C}$ Bucciarelli-Ducci. ${ }^{1}$ Bristol Heart Institute, University Hospitals Bristol NHS Foundation Trust., UK; ${ }^{2}$ Heart Lung Center, Department of Cardiology, Leiden University Medical Center, The Netherlands \\ 10.1136/heartjnl-2016-309668.21}

Background In aortic valve disease, left ventricular (LV) dimensions and ejection fraction are important parameters for decision making. However, the effects of pressure overload caused by aortic stenosis or/and volume overload, due to aortic regurgitation, lead to different LV remodelling, concentric and eccentric hypertrophy, respectively, which may differently alter LV mechanics. We aimed to characterise LV mechanics, in terms of longitudinal strain/deformation using feature tracking cardiac magnetic resonance (FT-CMR) in patients with various degree of aortic stenosis and aortic regurgitation and preserved LV ejection fraction (LVEF).

Methods Seventy-one patients (14 with normal valve function, 29 with aortic stenosis and 28 with aortic regurgitation), mean age $45 \pm 19$ years, $70 \%$ men, who underwent clinically indicated CMR and showed preserved LVEF (>50\%) were included. $\mathrm{LV}$ volumes, LVEF and mass were measured on steady-state free

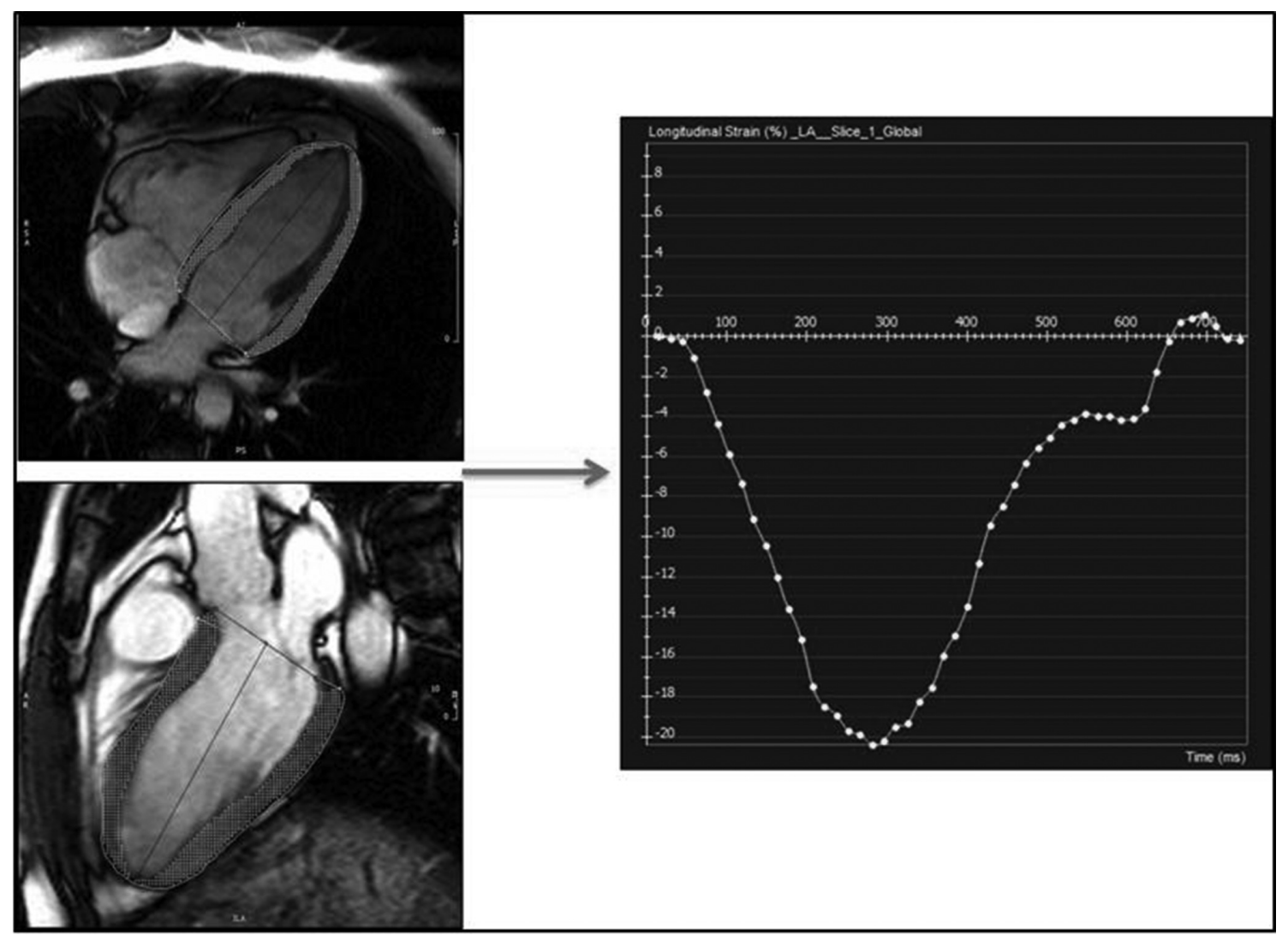

Abstract 21 Figure 1 Assessment of LV GLS with FT-CMR. From two long-axis SSFP cine images, the time-GLS curve is obtained and peak LV GLS is determined 